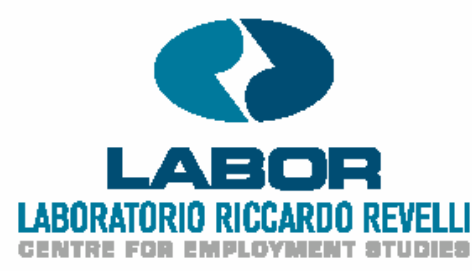

Working Paper no. 37

\title{
Toward a Non-Equilibrium Unemployment Theory
}

\author{
Matteo Richiardi \\ Laboratorio R. Revelli, Centre for Employment Studies
}

November 30, 2005 


\title{
Toward a Non-Equilibrium Unemployment Theory
}

\author{
Matteo Richiardi*
}

November 30, 2005

\begin{abstract}
This paper presents a non-equilibrium, agent-based model of workers and firms, with on-the-job searching, endogenous entrepreneurial decisions and endogenous wage and income determination. Workers and firms are heterogeneous, and learn their strategy in the labor market. The model is able to reproduce a number of stylized facts generally accepted in labor economics and industrial organization, such as the Wage, Beveridge and Okun curve, and the skewness of wage, income and firm size distribution. Most interestingly, important stylized facts such as a negatively sloped Wage Curve and a constant returns to scale matching function emerge only out-of-equilibrium, during the adjustment processes toward the stationary state. Thus, from a theoretical point of view the model suggests that taking these stylized facts as "building blocks" of equilibrium models might be misleading. The results stress two additional points. From a methodological point of view, the use of non-equilibrium computational models allows for a more comprehensive investigation of the labor market, by considering the endogenous character of many relevant variables. From an empirical point of view, the joint determination of all aggregate relationships and their dependence on the equilibrium or non-equilibrium state of the system suggest to move from the investigation of empirical regularities in isolation one from the other to a joint analysis.
\end{abstract}

Keywords: Unemployment, Entrepreneurship, Firm demography, Simulation, Beveridge, Okun, Wage Curve.

JEL Classification: J60, L11, C15.

*LABORatorio Riccardo Revelli Centre for Employment Studies, via Real Collegio 30, 10024 Moncalieri (Torino), Italy. Tel: +39-011.640.2660. Fax: +39.011.647.9643. Email: m.richiardi@labor-torino.it. This research has been partially funded by a grant MIURPRIN 2003 to the University of Torino. A Lagrange fellowship by ISI Foundation and CRT Foundation is also gratefully acknowledged. Preliminary versions of this paper were presented at the XIX Conference of the Italian Labour Economics Association in Modena, September 23-24 2004, at the Wild@Ace 2004 Conference in Torino, 3-4 December 2004 and at informal workshops at the University of Ancona, University of Pisa and ISI Foundation. I would like to thank in particular Roberto Leombruni, Giovanni Dosi, Giorgio Fagiolo, Roberto Gabriele, Mauro Sylos Labini and an anonymous referee for useful suggestions. I am also indebted to Michele Sonnessa, author of the JAS simulation platform, and to Jennifer Chubinski for their assistance. Usual disclaimers apply. 


\section{Introduction}

[I]f a model of unemployment conforms to the long-run equilibrium requirements of balanced growth, it is the most suitable starting point for the extensions that will eventually explain unemployment in real economies.

(C.A. Pissarides, Equilibrium Unemployment Theory, Preface to the First Edition)

This sentence contains both an act of faith and an admission of weakness. It recognizes that a macroeconomic equilibrium theory of unemployment such as the one described in the very well known book by Pissarides is not able to fully explain "real" unemployment. But it posits that any advance in the task will have to start from the methodological perspective of equilibrium analysis.

The present work aims to show that this may not be the case, and that important insights may be gained by non-equilibrium models. Here, non-equilibrium means that equilibrium is not imposed. Rather, it may emerge from the interaction of all individual behaviors, when some aggregate variables become stationary.

The non-equilibrium model developed in this paper is able to reproduce a number of stylized facts generally accepted in labor economics and industrial organization, such as the Wage, Beveridge and Okun curve, and the skewness of wage, income and firm size distribution. Most interestingly, important stylized facts such as a negatively sloped Wage Curve and a constant returns to scale matching function appear to be robust properties of the system only out-ofequilibrium, during the adjustment processes toward the stationary state.

The paper is structured as follows. Section 2 reviews the literature on unemployment theory. Section 3 sets up the model. Section 4 describes the computer simulation used to solve it, while section 5 presents the results. In particular, section 5.4 focuses on the stationary state properties of the system, section 5.5 describes the shocks that take the system out of its stationary state and finally section 5.6 deals with the out-of-equilibrium properties during the adjustment processes. Section 6 draws the conclusions and gives indication for future work.

\section{The literature}

In the economic literature, search models have become the standard reference for the analysis of unemployment. They originated from the work by Stigler [39] on the economics of information, who considered a buyer choosing the number of price quotations before beginning the search process, in order to minimize expected price plus sampling cost. Search models were first applied to labor issues, in a more dynamic perspective, with the work of Phelps et al. [30]. A surge in this strand of the literature occurred during the eighties, with major contributions by Diamond [13] [14] [15], Mortensen [23] [24], and Pissarides [32] [31]. Mortensen and Pissarides [26] and Pissarides [33] themselves provide extensive reviews of search models for the labor market. Search models rely on three pillars: the decision of workers, the decision of firms and the wage setting 
mechanism. Search activity is costly for individuals, who compare the utility of possibly getting a job with their actual utility (which may come from unemployment benefits, or from their present wage if on-the-job searching is allowed), thus computing the equivalent of an arbitrage equation for the valuation of an option (selling their unit of labor) in a perfect capital market. When two-sided search is considered, instead of considering an exogenous number of vacancies as in simpler models, the search process by firms is explicitly modeled. Vacancy opening is costly for firms. They thus make optimizing choices by comparing expected profits from posting a vacancy with those of leaving the growth opportunity unexploited. In a competitive economy these profits have to be null, allowing for simpler solutions. Wage setting follows two approaches. The most common considers a Nash bargaining solution, while the other approach considers wage posting by the firms. In both cases, a wage must eventually be set. Ideally, wages should also be endogenous, and lead to a right-skewed, long tailed wage distribution, as observed in the empirical evidence [27]. Diamond [12] was one of the first to address this issue. However, his model produces a single equilibrium wage, equal to the value of unemployment benefits, even if firms have different productivity levels. A number of models leading to non-degenerate wage distributions, both in the market for goods and in the market for labor, were subsequently developed. Firms offer higher wages in order to attract or retain more or better workers. A number of mechanisms, including on-the-job searching and workers heterogeneity (with respect to the utility derived from unemployment, or to productivity) can lead to such an outcome - see [36] for a detailed survey. Finally, ex-ante suitable jobs may include the entire stock of jobs (urn-ball matching) or, in case job seekers have complete information about available vacancies, may include only new jobs (stock-flow matching).

From an aggregate point of view the search activity leads to a matching function that (positively) relates the number of matches to the unemployment rate and the number of vacancies [6] [29]. The analysis of labor markets through aggregate matching models is a stream of research on its own. While search models have demonstrated the existence of equilibria in a decentralized wage setting with frictions, starting from the analysis of the micro-foundations of such a market, the matching function has focused on the flow of hiring, although from an aggregate point of view. Only recently have the links between micro-founded search models and the aggregate matching function been investigated [9] [37] $[21]$.

The common feature of all these models is that they are equilibrium models, with perfectly rational, optimizing agents. They are solved by imposing equilibrium conditions that simplify the structural equations of the model. Moreover, the need for analytical solutions forces the models to include only limited features: in standard search models firms do not exist, being totally replaced by vacancies, i.e. single-job entities ${ }^{1}$; job destruction is generally exogenously given; on-the-job searching, as the possibility of sending out multiple applica-

\footnotetext{
${ }^{1}$ this is where the separation between unemployment theory and firm demography comes from
} 
tions, is not allowed; entrepreneurial decisions are absent. These issues have been separately addressed, but only one at the time, due do the analytical intractability of more complicated models. ${ }^{2}$

However, despite providing important insights this stream of research has not been able to jointly account for multiple empirically observed "stylized facts". Set aside the paradoxical separation between matching theory and firm demography, with regularities such as the Power Law distribution of firm size and profitability [4] [18] [28] that remain largely unaddressed, the equilibrium theory of unemployment largely failed to jointly explain three well-documented aggregate properties of the labor market, i.e. the Wage, Beveridge and Okun curve [16]. The Wage Curve (WC) postulates a negative relationship between the average wage $\bar{w}$ and the unemployment rate $u$ [7] [11]. The Beveridge Curve (BC) postulates a negative relationship between the unemployment rate and the vacancy rate $v$, which shifts inward and outward during the transition periods. Finally, the Okun Curve (OC) describes a negative, linear and more than proportional relationship between the changes in the unemployment rate $\dot{u}$ and the GDP growth rate $g$ [34] [3]. While the Okun curve is mainly an empirical regularity and it is not clearly grounded in economic theory, the Beveridge curve is an equilibrium relation theoretically derived from the assumptions on the matching function (being the analogue of an isoquant for a production function). Its empirical evidence, however, is rather weak. The Wage curve, well grounded in the empirical evidence, is generally posited as one of the building blocks of imperfect labor markets, as a quasi-labor supply function ([11] however, remains skeptical). Its plausibility rests, for instance, on efficiency wages or union bargaining considerations. When interpreted as one side of the market, it gives rise to the usual identification issues, which suggest the use of adequate instruments.

A completely different approach has tried to jointly address all the points listed above by means of agent-based computational models. Agent-based models are computer programs that simulate the behavior of the basic entities in the system (i.e. workers and firms), given specific interaction rules. Aggregate behavior is thus reconstructed "from the bottom up". ${ }^{3}$ In particular, Dosi and co-authors [16] were able to reproduce the three aggregate curves described above with an evolutionary model focusing on the interactions of the firms with the output market. Gallegati and co-authors [19] worked in the direction of filling the gap between firm demography and unemployment theory by focusing on the interactions of the firms with the financial system.

In line with [35], the present work follows the agent-based computational economics (ACE) approach, and develops a simple model of the labor market with no interactions either with the output market or with the financial system. The model is characterized by heterogeneous agents, heterogeneous firms, entrepreneurship, on-the-job search, variable search effort and evolution-

\footnotetext{
${ }^{2}$ Models with endogenous job destruction include [1], [10] and [25]. On-the-job searching was first considered by [8] and [20]. Entrepreneurship has been the focus of [17]. Multiple applications have been considered by [2].

${ }^{3}$ For a methodological discussion on agent-based computational models, see [40] and [22].
} 
ary learning.

\section{The model}

The players in the model are individuals and firms. Individuals differ with respect to their productivity and their entrepreneurial attitude. They decide to either do nothing, search for a new job or start a new business. Firms differ with respect to their growth potential and their attitude toward workers. They decide how many vacancies to open and the wage they offer to applicants.

Workers and firms meet in a single labor market.

\section{$3.1 \quad$ Workers}

\subsubsection{Payoffs}

Wages (and wage offers) are a firm-specific constant share $\beta_{f}$ of the worker's productivity, which is assumed to be known to both sides. There are no unemployment benefits. Vacancy opening has a fixed cost of $C$ per vacancy. Thus, payoffs are as in equation 1.

$$
\begin{array}{ll}
\text { Unemployed } & : w_{U}=0 \\
\text { Employees } & : w_{E}=\beta_{f} \cdot p_{i} \\
\text { Employers } & : w_{S}=\sum_{i=1}^{N_{f, t}}\left(1-\beta_{f}\right) p_{i}-C \cdot V_{f, t}
\end{array}
$$

\subsubsection{Choices}

Each individual has an intrinsic productivity $p_{i} \in\left[p_{\min }, p_{\max }\right]$. Every period, she faces a two-stage decision. First, she must decide whether to remain passive, i.e. be content with her actual position, or active. If she is discontent with her actual position, either because she is unemployed or because she earns too little money, she must decide whether to look for a new position or to become an entrepreneur herself and start a new firm. These decisions are made by looking only at present and expected income, with expectations formed adaptively. The time horizon over which expectations are formed covers only one period ahead: thus, individuals do not take into consideration intertemporal trade-offs. The motivation behind this modeling choice is twofold. On one side, the desire to keep the model as simple as possible, especially since this is the first attempt to model the out-of-equilibrium properties of the labor market. On the other side, the consideration that it makes little sense to consider a longer time horizon when individuals form their expectations adaptively and do not engage in intertemporal optimization. 
Stay or Go To decide whether to become active and try to improve her income, each individual compares the expected income of staying in the present position, $w_{\text {stay }}^{e}$, with an individual threshold $L_{i}$ :

$$
\begin{aligned}
w_{\text {stay }}^{e} & =w_{i, t} \\
L_{i} & =\lambda_{i} \bar{w}_{t}
\end{aligned}
$$

where $w_{i, t}$ is the actual wage, $\bar{w}_{t}$ is the average wage of period $t$ and $\lambda_{i}$ is an individual constant. An individual becomes active if $w_{\text {stay }}^{e}<L_{i}$. Thus, individuals have adaptive expectations. Moreover, heterogeneity in $\lambda_{i}$ means that some individuals are more likely to be dissatisfied than others.

Search or Start Once an individual has become active, she decides whether to apply for another vacancy or to start a new business herself by comparing the expected payoff of becoming an entrepreneur, $w_{\text {start }}^{e}$ with an individual threshold $H_{i}$ :

$$
\begin{aligned}
w_{\text {start }}^{e} & =\left(\left(1-\beta_{f}\right) \bar{p}-C\right) V_{f, t} \\
H_{i} & =\eta_{i} \bar{w}_{t}
\end{aligned}
$$

where $\beta$ is the share of the productivity that the would-be entrepreneur is willing to leave to the prospective workers, $\bar{p}$ is the average productivity, $C$ is the cost of opening a vacancy and $V_{f, t}$ is the number of vacancies that the would-be entrepreneur plans to open. Finally, $\bar{w}_{t}$ is, as before, the average wage and $\eta_{i}$ is an individual constant. She thus expects (i) to fill all the vacancies, and (ii) that the workers in the new firm will average the same productivity as in the population, which in turn is supposed to be known. A new startup is formed if $w_{\text {start }}^{e}>H_{i}$. In order to increase the realism of the model, the Start option is available only if the individual has a positive income at the time of the choice, i.e. if she was employed in the previous period ${ }^{4}$. An active individual that does not try to set up a business on her own starts sending out applications to other vacancies. The search effort is modeled by a parameter $a$, which controls for the number of applications that she is able to send each period.

\subsection{Firms}

\subsubsection{Vacancies and growth}

In order to compute $w_{\text {start }}^{e}$ in eq. 3 , an individual must decide how many vacancies to open in the case of a new startup. It is assumed that each time an individual faces this choice, she has in mind a desired dimension $\nu_{f}$ for the startup. This desired dimension may be related to the minimum efficient scale for the new business. Heterogeneity in $\nu_{f}$ accounts for heterogeneity in the

\footnotetext{
${ }^{4}$ at the moment of making the choice an individual with positive income can thus be either employed or, in case her firm was closed after the previous period, unemployed (see figure 1 below for the sequence of events). However, long-term unemployed cannot become entrepreneurs.
} 
business ideas, in the entrepreneurial talent, in the sectors of activity. Each period a firm opens the closest integer number of vacancies to

$$
V_{f, t}=\delta\left(\nu_{f}-N_{f, t-1}\right)
$$

where $N_{f, t-1}$ is the size of the firm at the previous period (it is 0 at the startup) and $\delta$ is a gap-filling rate.

Entrepreneurial talent is thus summarized by 2 parameters: $\nu_{f}$, the desired size for the prospective startup, and $\beta_{f}$, the Nash bargaining threshold in wage setting. These parameters change every time the individual faces the choice of becoming an entrepreneur, as many different business models may be taken into consideration.

\subsubsection{Death}

Firms die because all employees decide to leave, or because they make negative profits. They cannot finance negative periods with the profits they have possibly saved in previous positive periods. ${ }^{5}$ It is assumed that when a firm goes bankrupt it is still able to pay wages. However, all employees become unemployed.

\subsection{Matching}

Job seekers apply to vacancies randomly. Vacancies can receive multiple applications. For each vacancy, applicants are ranked by their productivity, which is assumed to be certain and known to both sides (no asymmetric information). Firms try first to hire the most productive worker, by offering her the firmspecific share of her productivity. The worker accepts only if she is proposed a wage increase. The model thus allows for on-the-job searching. Moreover, this mechanism implies that a worker can receive multiple offers in one period, and choose the best one.

\subsection{Transition matrix}

The rules described above define a transition matrix between four different states: unemployment with zero or negative income $\left(U_{0}\right)$, unemployment with positive income $\left(U_{+}\right)$, employment $(E)$ and self-employment $(S)$. The events that drive each transition are listed in table 1 . The Appendix reports all transition probabilities. However, they are not stationary, and thus it is not possible to compute the long-run limiting distribution of the underlying Markov chain using the global balance equations. ${ }^{6}$

\footnotetext{
${ }^{5}$ It could be argued that a firm should be closed when the payoffs for the entrepreneur are lower than those expected from becoming an employee. However, entrepreneurial decisions in the real world are often characterized by inertia: otherwise, we would not be able to explain bankruptcy. Considering both causes of firm closure would add too complication to the model: hence the decision to focus only on bankruptcy.

${ }^{6}$ An example of a search model for which the global balance equations have been used to solve for the equilibrium is [35].
} 


\begin{tabular}{|c|c|c|c|c|}
\hline & \multicolumn{4}{|c|}{ Ending state } \\
\hline $\begin{array}{l}\text { Starting } \\
\text { state }\end{array}$ & $\overline{U_{0}}$ & $\overline{U_{+}}$ & $E$ & $S$ \\
\hline$U_{+}$ & $\begin{array}{c}\text { (Search } \\
\text { AND Unsuccessful search) } \\
\text { OR } \\
\text { (Start AND Startup closure) } \\
\end{array}$ & $\begin{array}{l}\text { (Search } \\
\text { AND Successful search } \\
\text { AND New firm closure) }\end{array}$ & $\begin{array}{c}\text { Search } \\
\text { AND Successful search } \\
\text { AND New firm survival }\end{array}$ & Start AND Startup survival \\
\hline$E$ & Start AND Startup closure & $\begin{array}{c}\text { (Stay AND Firm closure) } \\
\text { OR } \\
\text { (Search } \\
\text { AND Unsuccessful search } \\
\text { AND Old firm Closure) } \\
\text { OR } \\
\text { (Search } \\
\text { AND Successful search } \\
\text { AND New firm Closure) }\end{array}$ & $\begin{array}{c}\text { (Stay AND Firm survival) } \\
\text { OR } \\
\text { (Search } \\
\text { AND Unsuccessful search } \\
\text { AND Old Firm survival) } \\
\text { OR } \\
\text { (Search } \\
\text { AND Successul search } \\
\text { AND New firm survival) }\end{array}$ & Start AND Startup survival \\
\hline$S$ & $\begin{array}{c}\text { (Stay } \\
\text { AND Own firm closure) } \\
\text { OR } \\
\text { (Search } \\
\text { AND Unsuccessful search } \\
\text { AND Own firm closure) } \\
\text { OR } \\
\text { Start AND Startup closure }\end{array}$ & $\begin{array}{l}\text { Search } \\
\text { AND Successful search } \\
\text { AND New firm closure }\end{array}$ & $\begin{array}{l}\text { Search } \\
\text { AND Successful search } \\
\text { AND New firm survival }\end{array}$ & $\begin{array}{c}\text { (Stay } \\
\text { AND Own firm survival) } \\
\text { OR } \\
\text { (Search } \\
\text { AND Unsuccessful search } \\
\text { AND Own Firm survival) } \\
\text { OR } \\
\text { (Start } \\
\text { AND Startup survival) }\end{array}$ \\
\hline
\end{tabular}

Table 1: State Transition Matrix 


\begin{tabular}{ccl}
\hline Parameter & Range & Meaning \\
\hline \multicolumn{2}{c}{ Environmental Parameters } \\
$D_{p}$ & \multicolumn{3}{c}{ Productivity distribution } \\
$C$ & $R_{+}$ & Vacancy opening cost \\
$\delta$ & $(0,1]$ & Gap-filling rate \\
$a$ & $R_{+}+$ & Search intensity
\end{tabular}

Choice Parameters

\begin{tabular}{ccl}
$\lambda_{i}$ & $R_{+}$ & Low wage threshold \\
$\eta_{i}$ & $R_{+}$ & High wage threshold \\
$\beta_{f}$ & {$[0,1]$} & Nash share \\
$\nu_{f}$ & $R_{++}$ & Desired size \\
\hline
\end{tabular}

Table 2: Parameters

\subsection{Model's parameters}

As we have seen, the model has 8 parameters, of which 4 are choice variables. They are summarized in table 2 .

$\lambda_{i}$ and $\eta_{i}$ account for risk aversion. Having a lower value for $\lambda_{i}$ implies an individual is less likely to be dissatisfied and thus become active. Having a higher value for $\eta_{i}$ implies an individual is less keen on becoming an entrepreneur. $\beta_{f}$ and $\nu_{f}$ fully characterize firms. $\beta_{f}$ refers to how aggressive a firm is toward its employees. Having a lower value for $\beta_{f}$ implies the firm keeps a higher share of the total productivity, which is good for profits. However, since it pays lower wages it is less likely to attract and retain workers. Vacancies are thus more difficult to fill, which is bad for profits. Similarly, having a higher value for the desired size $\nu_{f}$ implies more profit opportunities but more risk to have unfilled vacancies. Good firms have good combinations of these two parameters. But such profitable combinations will of course change with time, being a function of the distribution of the $\beta_{f}$ and the $\nu_{f}$ in the population of firms and the distribution of the productivity $p_{i}$, the $\lambda_{i}$ and the $\eta_{i}$ both of employed and of unemployed workers.

As already noted, $\beta_{f}$ and the $\nu_{f}$ are firm-specific. Thus, the same individual may try to create different startups with different values of these parameters.

\subsection{Optimization}

The values of the $\lambda_{i}$, the $\eta_{i}$, the $\beta_{f}$ and the $\nu_{f}$ are optimized through evolutionary learning. Firms with negative profits exit the market, with their bad combinations of the Nash share and desired size. Individuals with lower income update their behavior by drawing (randomly) a different value for the lower and 
higher wage thresholds. This is a form of very primitive optimization, since new strategies are not influenced by the existing ones. ${ }^{7}$

\section{Solution of the model}

The dynamics of the model is investigated by means of an agent-based simulation. Note that in a simulation model, like in reality, it is not easy to let the agents behave as if some equilibrium condition has to be met. Agents must be able, at each point in time, to compute their action, given their state, the state of (some) other agents and possibly history. Imposing equilibrium conditions forces the system to "jump" to the equilibrium. This is the standard way to proceed in analytical models, since adding equilibrium conditions generally simplifies the equations, allowing algebraic solutions. But it may happen than by imposing directly the equilibrium from the outset we loose some interesting properties of the out-of-equilibrium adjustment path. An alternative way of defining the equilibrium is to let it emerge, and look for the stationarity of some aggregate variables, given detailed micro-rules that specify the agents' behavior and the interaction structure. This is the approach followed in this work, which calls for the use of an agent-based simulation. Indeed, this work has to be regarded as an example of what might get lost when using the traditional approach of imposing the equilibrium conditions as a way to "solve" the model.

The simulation is written in Java and is based on the JAS platform [38]. ${ }^{8}$

Figure 1 reports the event schedule of the simulation. There are four basic entities: workers, firms, vacancies and the environment (named "the model") from which the simulation is controlled. Each period, firms with negative profits are closed down (by the closeNegativeProfitFirms method), unfit agents evolve and draw a new set of parameters $\lambda_{i}$ and $\eta_{i}$ (evolveUnfitAgents). Then, each existing firm posts the new vacancies, if any (postVacancies). After this step, every individual decides what to do, by invoking the two methods shouldIStayOrShouldIGo and - conditional on becoming active - shouldIStartOrShouldISearch. After all agents have made up their mind, those who have decided to become entrepreneurs start their own business (start), and open additional vacancies (with a call to the already known postVacancies method). Now that all vacancies are posted, those agents who wish to search for a new job post their applications (search). Then firms select the candidates, if any, for their vacancies (selectApplicant), produce (produce) - which sums up all employees' productivities - and finally divide the output between wages and profits (pay).

\footnotetext{
${ }^{7}$ More sophisticated specifications of the learning process, for instance by means of genetic algorithms, have been tested but do not alter qualitatively the results of the model. They do introduce, however, the possibility of multiple stationary states.

${ }^{8}$ The simulation code is available from the author upon request.
} 


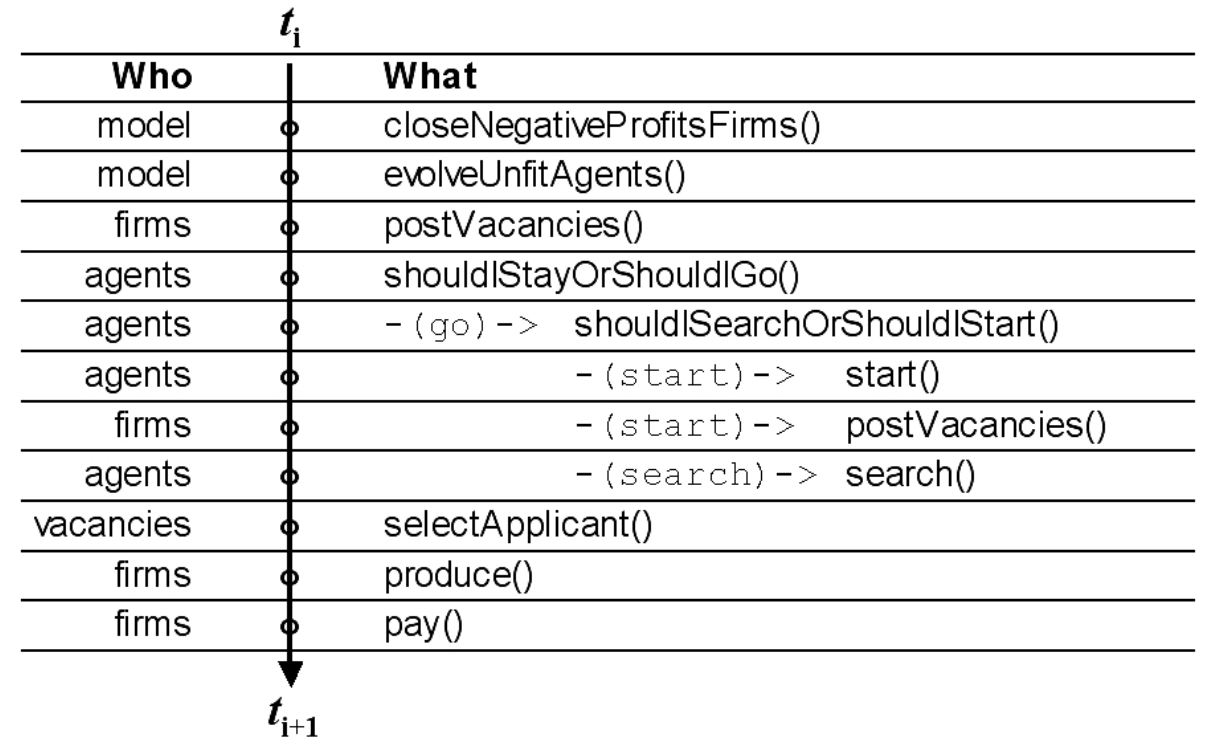

Figure 1: Event schedule

\section{Results}

\subsection{Parameters and initial conditions}

Here are the values of the parameters used in the simulation. In $t=0$ (initial conditions) everybody is unemployed and there are no firms. Individual productivity is a random extraction from a uniform distribution $U(0,10) .{ }^{9} \lambda_{i}$ is a random extraction from $U(0,1)$. $\eta_{i}$ is a random extraction from $U(1,2)$. $\beta_{f}$ is a random extraction from $U(0,1)$. Desired size is a random extraction from $U(0, N / 10)$, where $N$ is the number of agents (generally 1000). The fixed cost of opening a vacancy, $C$, is kept constant at 2 , i.e. $40 \%$ of the average productivity. The gap-filling rate $\delta$ is equal to 0.5 . Two additional constraints are added to the rule for vacancy determination, to increase the realism of the model. The maximum number of vacancies a firm can open at its startup is limited to 10 , while in subsequent periods it is limited to the actual size of the firm

\footnotetext{
${ }^{9}$ Many empirical studies point out that individual productivity is far from being uniformly distributed, and a lognormal approximation is generally assumed. Here however, the point is to show that a uniform distribution for productivity is sufficient to generate a skewed distribution for wages. Individual wages are linked to individual productivity, but the selection effect is such that a skewed distribution of wages for employed people emerges (see figure 7 below). Note that the only effect of scaling up (or down) the productivity distribution is to proportionally scale up (or down) the wage distribution and aggregate production. More interesting effects come from changing the shape of the productivity distribution. A wider distribution (more heterogeneity) implies more turbulence in the labor market, as more people become unsatisfied with their wage and try to change their job.
} 


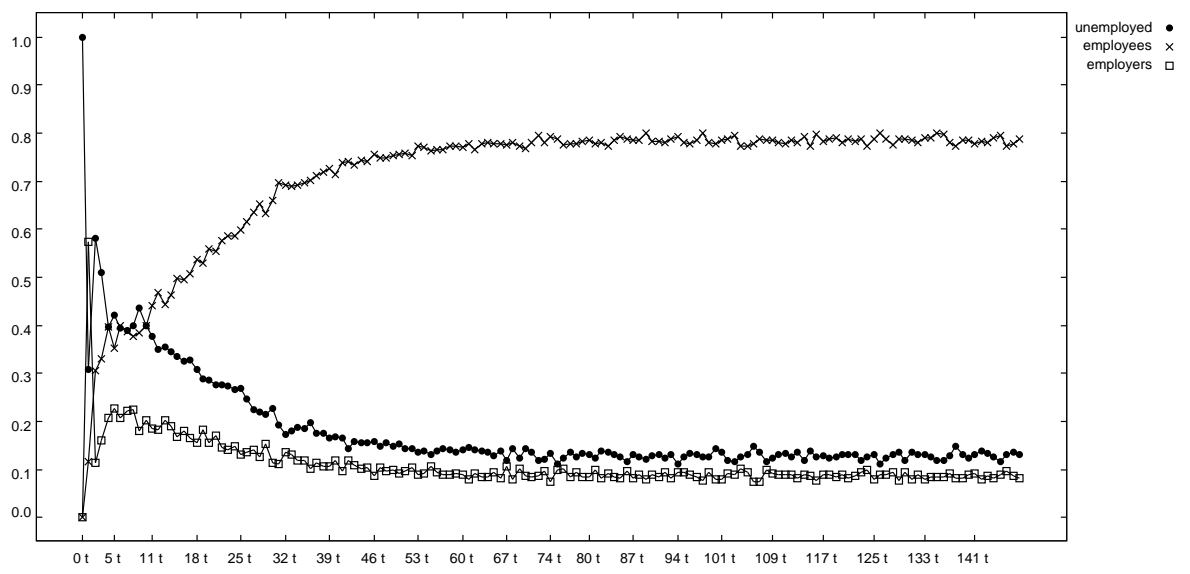

Figure 2: State probabilities

(the growth rate cannot exceed 1). A first calibration of the model suggested choosing a value for search intensity (the number of applications an individual can send each period) of 0.3 , i.e. 1 application every 3 periods, on average ${ }^{10}$. Finally, individual learning involves the poorest quartile of the population, in terms of income.

\subsection{Convergence}

Figure 2 shows how the system converges to a stationary state. Starting from a 0 -employment situation, the equilibrium unemployment rate for the values of the parameters described above is around $13 \%{ }^{11}$; about $78 \%$ of the population is employed ${ }^{12}$, while the remaining $9 \%$ have become entrepreneurs. This (unique) stationary state is reached irrespective of the initial conditions.

Note that the system has very few degrees of freedom. Of the eight parameters in table 2 , four (the choice parameters) are endogenously determined. $\delta$, the gap-filling rate affects only the speed of convergence. Holding constant productivity distribution, there are only two parameters left: the vacancy opening cost $C$ and the search intensity parameter $a$. Figure 3 shows what happens when search intensity is increased, for increasing values of the vacancy cost. A higher search intensity lowers the stationary state unemployment rate, while bigger vacancy costs increase it. All other dynamics remain qualitatively unaffected. Note that when $C$ reaches the values of 5 the stationary state unemployment

\footnotetext{
10 the reader could think in terms of weeks

${ }^{11}$ sticking to the interpretation of 1 period $=1$ week, this value is an upper bound for the "true" unemployment rate, since the definition of unemployment generally refers to non employment in the last 4 weeks

12 excluding entrepreneurs
} 


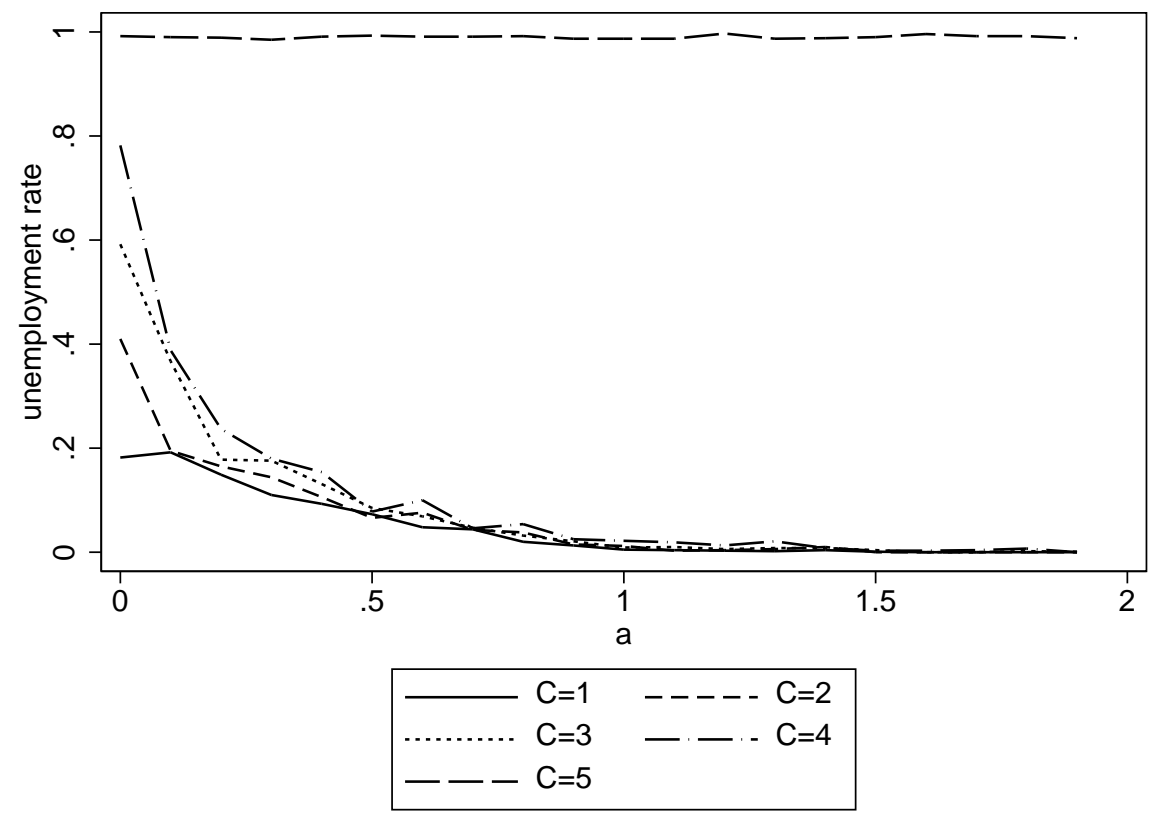

Figure 3: Stationary state, sensitivity analysis

rate jumps to 1 . This is due to the fact that the expected value of filling one vacancy, given the productivity distribution, is exactly 5 . Nobody will then open new vacancies.

Learning is seen by a change in the average value of the 4 choice parameters (figure 4). The system needs about 100 periods to stabilize. The stationary average values for $\lambda$ and $\eta$, the low and high income thresholds, are about .46 and about 1.45 , while the average $\beta$ converges to a value of about .74. Note that the average desired size $\nu$ for employers is different (actually lower) than the one for unemployed workers, meaning that the model is able to discriminate between good and bad entrepreneurs. Moreover, the average value for the productivity of employed workers is higher than for unemployed workers (figure 5). This is due $(i)$ to the rule for applicant selection, and (ii) to the fact that wages are proportional to productivity, and thus workers with higher productivity are less likely to be dissatisfied and thus start a risky entrepreneurial activity themselves.

\subsection{Identification issues}

I now turn to the problem of identifying a Wage curve in the artificial data. If one considers the WC simply as an empirical regularity, looking at the correlation between wages and unemployment (once other relevant variables as the 

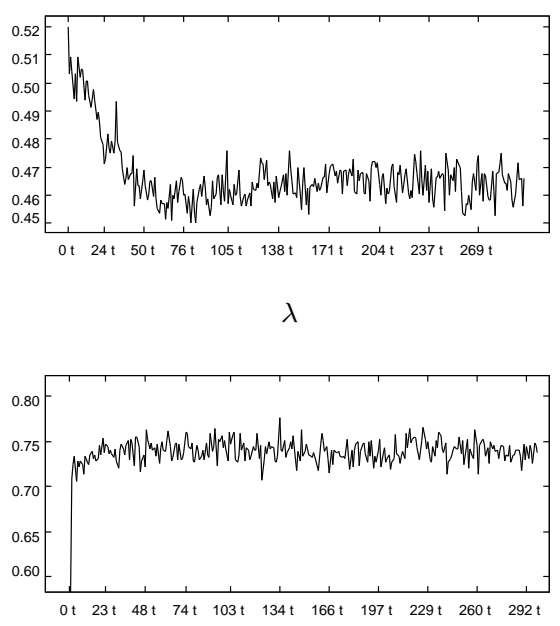

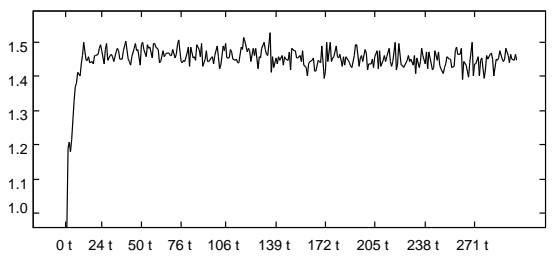

$\eta$

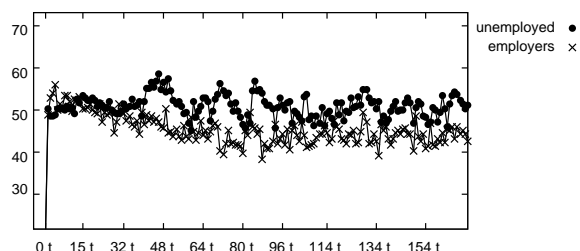

$\nu$

Figure 4: Choice parameters, average values

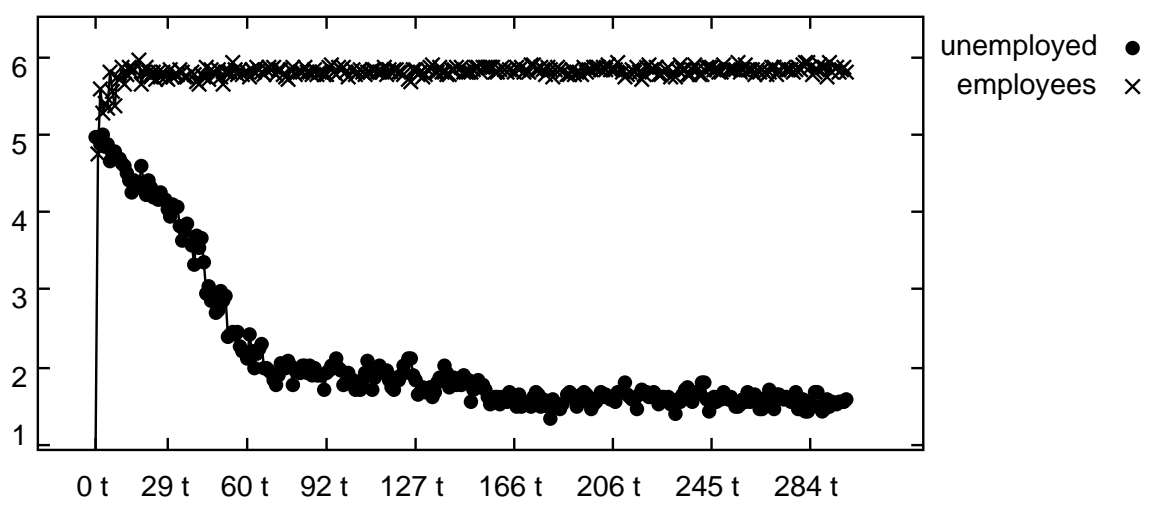

Figure 5: Productivity, average values 
productivity level are taken into account) is enough. However, the alternative approach to treat the WC as a quasi-labor supply function implies the need to distinguish, in the artificial as well as in the real data, between aggregate demand and supply. Recall that the decision of becoming active depends on expected wages. Once individuals are active, they must choose between becoming self-employed or looking for vacancies: the choice of becoming self-employed depends on the average productivity, while the decision to accept a job offer depends entirely on the proposed wage, which in turns depends on productivity. Thus, individual (and aggregate) labor supply depends on wage and productivity, as in the standard Wage curve setting [5]. On the other hand, the demand for labor of individual firms does not depend neither on wages nor on productivity. However, since some firms go bankrupt and bankruptcy depends also on the wage bill and the productivity of employed workers, the aggregate demand for labor turns out to depend on these two variables too, and an identification problem arises. Fortunately, the aggregate labor demand depends also on the distribution of the $\nu$ parameter (desired size), whose evolution is only weakly correlated to wages and productivity. Thus, the variation of this parameter allows the identification of the WC, once controlling for the productivity of employed workers.

\subsection{Equilibrium}

As shown above, the system reaches its stationary state after approximately 75-100 periods. To investigate its equilibrium properties, the first 150 periods are discarded; then, artificial data from $t=150$ to $t=300$ are analyzed. ${ }^{13}$

Figure 6 shows the standard aggregate properties concerning the labor market. Both the Beveridge curve and the Okun curve have the expected negative slope, although the OC looks flatter than in the empirical evidence. The Wage curve shows a positive slope: however, after controlling for productivity the slope becomes not significant. The intuition behind this behavior is simple. In the steady state, the probability of a firm going bankrupt is inversely proportional to the productivity of its employees. Hence, dismissed workers have on average a lower productivity than workers in surviving firms. At an aggregate level, this implies that a higher unemployment rate corresponds to a higher average productivity. Since wages are directly related to productivity ( $\beta$ being constant in the stationary state), this explains their positive correlation with unemployment, which however vanishes after controlling for productivity.

10 runs are performed, and for each of them simple regressions are run over the periods $t=150-300$ in order to test for the slope of the three curves. The regression models for the $\mathrm{BC}$ and $\mathrm{OC}$ have just one independent variable

\footnotetext{
${ }^{13}$ Note that in the perspective of equilibrium models, every point of an equilibrium relation is a fixed point, for particular values of the parameters. Assuming the real world is in equilibrium, we could typically observe the curve described by the model by looking at cross-sectional data. On the other hand, in the stationary state of a non-equilibrium, stochastic model like this one every period corresponds to a point in the stationary state relationship. Assuming the real world is stationary, we could typically observe the curve described by the model by looking at time-series data.
} 

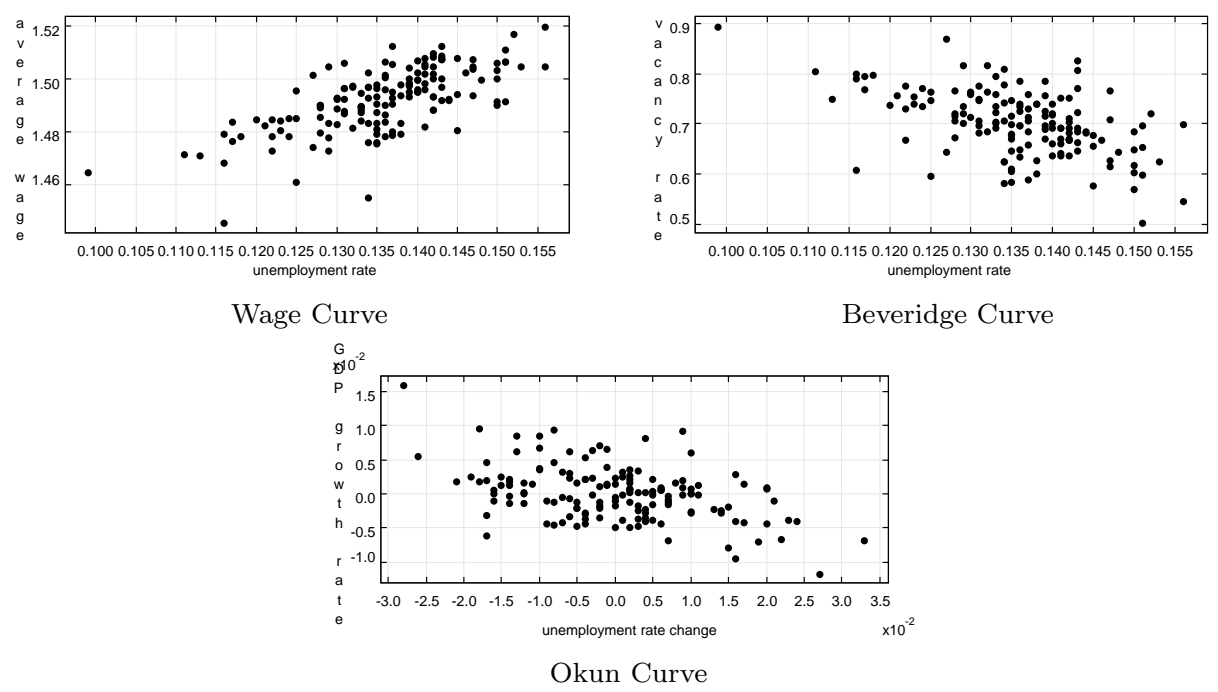

Figure 6: Wage, Beveridge and Okun curve, stationary state

(respectively, the vacancy rate and the GDP growth rate), plus the constant. When looking for the WC I also control for the average level of productivity of employed workers. Table 3 shows that the regularities described above are fairly robust. For each curve, the average slope and the standard deviation of the coefficients across all simulation runs is reported ${ }^{14}$, at the end of the table. 15

Until now, the model has shown a behavior roughly in line with standard equilibrium search models. But having an agent-based simulation model, it is easy to investigate other implicit properties of the model, in particular concerning firm demography, wages and profits.

A graphical inspection of firm size, wage and profit distribution (figure 7) shows the typical asymmetric shapes normally considered as stylized facts in the industrial organization literature. The large number of firms with negative profits refers to the entrepreneurs who try to set up their own startup and fail, generally within one single period. Note that the shape of the wage distribution is not an artifact of the model, since we started with a uniform distribution for individual productivity, on which wages are based.

\subsection{The experiments}

Once the system has converged to its stationary state, two kinds of negative shocks are simulated. The first one involves the exogenous destruction of $5 \%$ of

\footnotetext{
${ }^{14}$ note that the standard deviation of the coefficients is not the average of the standard errors

${ }^{15}$ Further details on the regressions results can be obtained from the author upon request.
} 


\begin{tabular}{lccc}
\hline time & $150-300$ & & \\
& WC & BC & OC \\
$y$ & $\bar{w}$ & $v$ & $g$ \\
$x$ & $u$ & $u$ & $\dot{u}$ \\
\hline run & \multicolumn{2}{c}{ sign of the coeff. } \\
0 & & --- & --- \\
1 & & --- & --- \\
2 & & --- & -- \\
3 & & --- & --- \\
4 & & --- & --- \\
5 & & --- & --- \\
6 & & --- & --- \\
7 & & --- & --- \\
8 & \multicolumn{4}{c}{---} & --- \\
9 & & --- & --- \\
\hline average & -0.025 & -4.012 & -0.123 \\
std.dev. & 0.115 & 0.601 & 0.039 \\
\hline$* * *$ & confidence interval $>.99$ \\
$* *$ & confidence interval $>.95$ \\
$*$ & confidence interval $>.90$ \\
$*=\{+,-\}$ & &
\end{tabular}

Table 3: Wage, Beveridge and Okun curve, stationary state

the firms, irrespective of size, age, profits or any other firm attribute (random closure). The second one refers to a $5 \%$ probability of any worker being fired, irrespective of individual or firm characteristics (random firing). Both events persist over time, until a new stationary state is reached. Figure 8a shows the time series for the unemployed, the employed and the self-employed for one simulation run. At $t=300$ the first shock arrives and persists for 50 periods, after which the system slowly goes back to the previous stationary state. The second shock arrives at $t=500$, also to last for 50 periods. Note that it takes some time for the new adverse conditions to display all their effects. However, the time needed to absorbe the shock, once the previous conditions are restored, is much longer. Note also that the effects of the first shock, the random closure of firms, are stronger than those of the second shock, the random firing of employees.

The two types of shocks differ in one, very significant, way. While an increased probability of being fired does not have a disruptive, systemic effect until this probability becomes very high, randomly closing down some firms exhibits a typical threshold effect. When the share of firms exogenously closed is sufficiently low, nothing happens. But when this share exceeds a critical level, the system reorganizes on a new stationary state with a much higher unemployment rate, as in figure $8 \mathrm{a}$. Figure $8 \mathrm{~b}$ supports this argument by showing what happens with smaller shocks. The two shocks described above now involve, respectively, only $1 \%$ of the firms and $1 \%$ of the employees. The first shock is immediately 


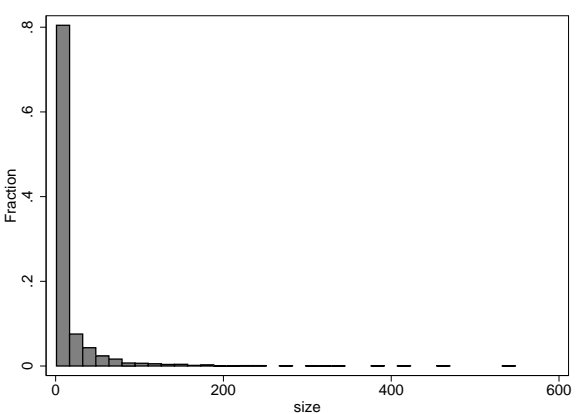

Firm size distribution

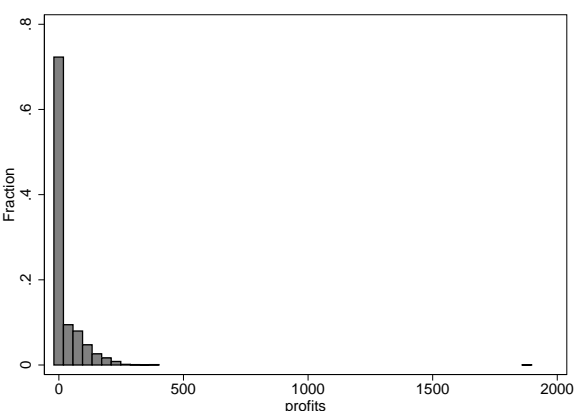

Profit distribution

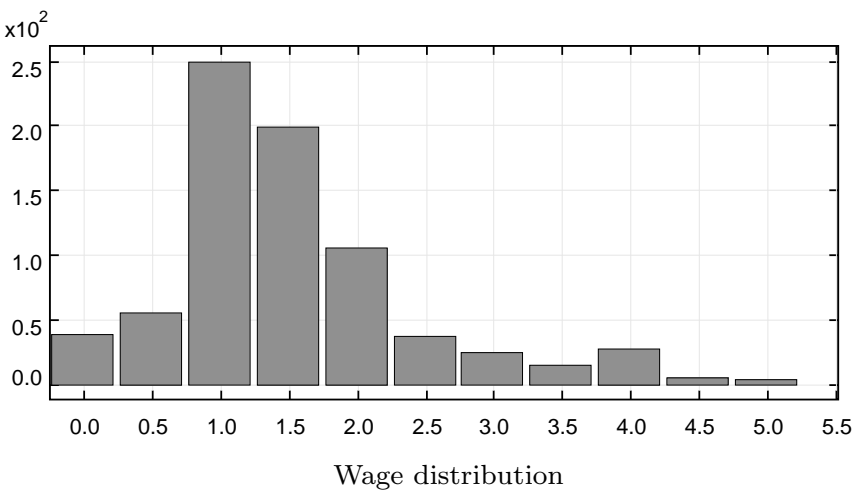

Figure 7: Firm size and income, stationary state

absorbed, and is not detectable in the artificial data $(t=300-350)$, while the second one still has a negative impact on the unemployment rate $(t=500-550)$, although less than in the previous case.

In the new perturbed steady state the system exhibits the same qualitative behavior as in the unperturbed steady state: the Wage curve does not show up, while the Beveridge and the Okun curves maintain their negative slope. However, the BC is shifted outwards, as is often documented in the empirical evidence, and the Okun curve is steeper.

\subsection{Out-of-equilibrium dynamics}

It is now interesting to see how the system reacts when the two exogenous perturbances are removed, and the system goes back to its original stationary state. After graphical inspection, it was decided to focus on a 150-period interval after the end of the first shock $(t=350-500)$, and on a 100-period interval after the end of the second shock $(t=550-650)$.

In particular, it is interesting to see whether the shape of the Wage, Beveridge and Okun curve and the matching function change, and how. The fol- 


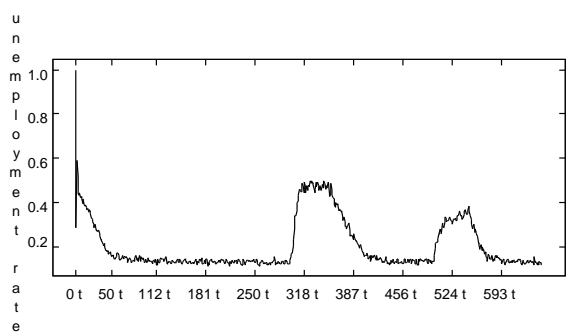

(a)

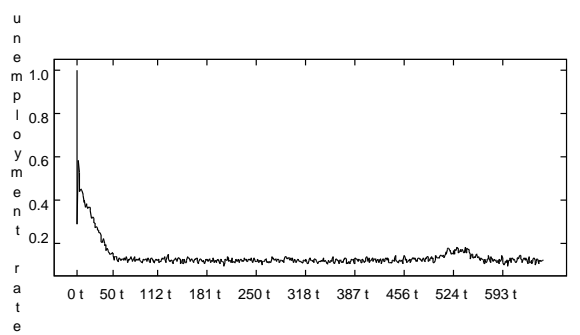

(b)

Figure 8: Effects of adverse shocks

lowing paragraphs are devoted to each of these issues.

\subsubsection{Wage, Beveridge and Okun curve}

Figure 9 depicts the three curves after the end of the first shock, for one simulation run.

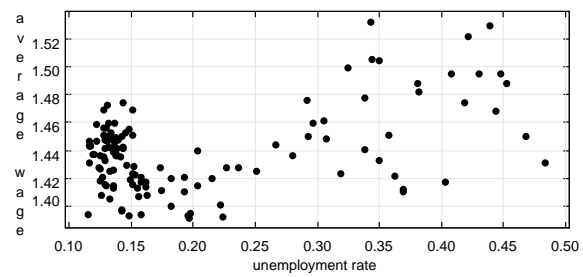

Wage Curve

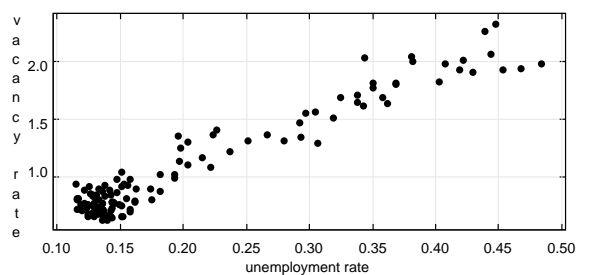

Beveridge Curve

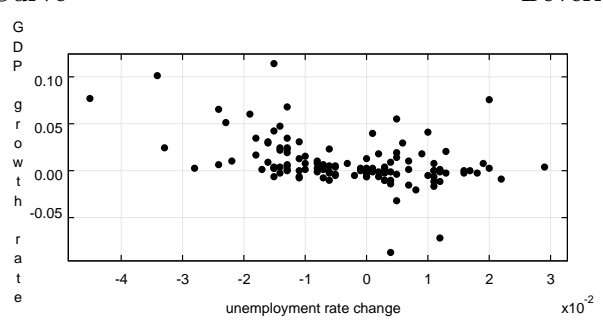

Okun Curve

Figure 9: Wage, Beveridge and Okun curve, out-of-equilibrium

At the beginning of the adjustment process, when the unemployment rate is still far from its equilibrium value, the Wage Curve points south-west. Toward the end of the adjustment process, when the unemployment rate gets closer to its equilibrium value, the WC starts pointing north-west, thus exhibiting a negative slope. Finally, when the system reaches its stationary state again, the WC starts behaving again as described in section 5.4. The plots show the raw correlation between wages and unemployment. After controlling for 
productivity, the positive slope found at the beginning of the adjustment process looses significance in some runs. However, the negative slope during the finetuning of the adjustment process remains highly significant. At the same time, the Beveridge Curve shows an inward shift, that slows down toward the end of the adjustment process. Eventually, the BC recovers its traditional negatively sloped shape. The Okun Curve on the other side keeps its negative slope through all the adjustment processes.

These first, descriptive findings are analyzed more in depth by running again simple regressions on the artificial data coming from the same 10 simulation runs. The length considered for the adjustment process to take place is kept constant throughout all the simulation runs (see above). Similarly, the turning point for the Wage Curve is supposed to take place at $u=0.2$ for all the simulation runs. These two simplifications may have an adverse effect on the results of the regressions, since in each simulation run the transient dynamics of the system change slightly. So, it may happen that for some simulation runs the adjustment process actually takes less (or more) than 150 periods after the end of the first shock and 100 periods after the end of the second shock. The analysis may thus either mix together data from the out-of-equilibrium adjustment process with data that already belongs to the unperturbed stationary state, or consider a still incomplete adjustment process. The division between a first and a second part of the adjustment process, relevant for the Wage Curve, is also somehow arbitrary and does not take into consideration the specific adjustment process taking place in each simulation run. More sophisticated econometric techniques could be used to detect the structural breaks in the data. However, using a one-for-all, visual criterium turns out to be sufficient for the scope of this analysis.

Table 4 reports the results of the regressions for the adjustment processes after the removal of the two shocks. They confirm the dynamics described above. For each curve, the average slope across all simulation runs is reported, together with the standard deviation, at the end of the table. ${ }^{16}$

The intuition why a negative correlation between wages and unemployment is found only out-of-equilibrium is the following. When the unemployment rate is abnormally high, firms can afford paying lower wages (retaining a higher share $\beta$ of the workers' surplus), since they will still be able to attract some applicants. However, as unemployment is driven back and the labor market becomes tighter, competition makes it easier for firms offering higher wages to attract a higher share of the workforce. Thus, decreasing unemployment is correlated with increasing wages, climbing up a negatively sloped Wage Curve. This mechanism is shown in figure 10, where individual $\beta$ s are weighted by firm size. Note that the average $\beta$ does not start to decrease immediately after the shock is removed at time $t=350$ : there is a period of decreasing unemployment when the labor market is still slack enough and firms face only limited competition in attracting new workers or retaining existing employees. This explains why a negative Wage Curve is recovered only in the final stages

\footnotetext{
${ }^{16}$ Further details on the regression outputs can be obtained from the author upon request.
} 


\begin{tabular}{|c|c|c|c|c|c|c|c|c|}
\hline \multirow[t]{2}{*}{ time } & \multicolumn{4}{|c|}{$350-500$} & \multicolumn{4}{|c|}{$550-650$} \\
\hline & \multicolumn{2}{|c|}{ WC } & $\mathrm{BC}$ & $\mathrm{OC}$ & \multicolumn{2}{|c|}{ WC } & $\mathrm{BC}$ & $\mathrm{OC}$ \\
\hline$y$ & \multicolumn{2}{|c|}{$\bar{w}$} & $v$ & $g$ & \multicolumn{2}{|c|}{$\bar{w}$} & $v$ & $g$ \\
\hline \multirow[t]{2}{*}{$x$} & \multicolumn{2}{|c|}{$u$} & $u$ & $\dot{u}$ & \multicolumn{2}{|c|}{$u$} & $u$ & $\dot{u}$ \\
\hline & $u \geq .2$ & $u<.2$ & & & $u \geq .2$ & $u<.2$ & & \\
\hline run & \multicolumn{8}{|c|}{ sign of the coeff. } \\
\hline 0 & +++ & --- & +++ & --- & +++ & -- & +++ & --- \\
\hline 1 & +++ & --- & +++ & --- & & & +++ & --- \\
\hline 2 & +++ & -- & +++ & --- & & --- & +++ & --- \\
\hline 3 & & --- & +++ & --- & +++ & -- & +++ & --- \\
\hline 4 & +++ & --- & +++ & --- & & --- & +++ & --- \\
\hline 5 & & --- & +++ & --- & & --- & +++ & --- \\
\hline 6 & +++ & --- & +++ & --- & + & & +++ & --- \\
\hline 7 & & --- & +++ & --- & - & --- & +++ & --- \\
\hline 8 & +++ & --- & +++ & --- & & & +++ & --- \\
\hline 9 & +++ & --- & +++ & --- & & --- & +++ & -- \\
\hline average & .341 & -.515 & 4.223 & -.739 & .066 & -.223 & 4.337 & -.427 \\
\hline std.dev. & .300 & .255 & .315 & .213 & .315 & .167 & .426 & .101 \\
\hline $\begin{array}{l}* * * \\
* * \\
* \\
*=\{+,-\}\end{array}$ & $\begin{array}{l}\text { confide } \\
\text { confide } \\
\text { confide }\end{array}$ & $\begin{array}{l}\text { e inter } \\
\text { e inter } \\
\text { e inter }\end{array}$ & $\begin{array}{l}1>.99 \\
1>.95 \\
1>.90\end{array}$ & & & & & \\
\hline
\end{tabular}

Table 4: Wage, Beveridge and Okun curve, back from shocks 1 and 2

of big adjustment processes, or for small adjustment processes.

\subsubsection{The matching function}

Until now, nothing has been said about the matching function implied by the model. However, we know that the existence of an aggregate (positive) relationship between vacancies and unemployment, on one side, and job creation on the other side has played a crucial role in the first formulations of the equilibrium unemployment theory (see [33]). The standard model actually assumes it, often together with the additional restriction of a Cobb-Douglas functional form with constant returns to scale (c.r.s.). A huge stream of literature then looked at the empirical data, in order to test for this crucial claim [29]. Estimates of a c.r.s. matching function - often of the Cobb-Douglas type - have been taken as proof that the standard search model, which used it to derive equilibrium relations, was "correct".

To test the properties of the matching function in the model, a Cobb-Douglas was fitted on the artificial data coming from the 10 simulation runs. As table 5 shows, the model fails to derive a well-behaved matching function, in the stationary state. The unemployment rate $(u)$ and the vacancy rate $(v)$ even have a negative impact on the matching rate $(m)$. However, during the adjustment process the matching function exhibits all the desired properties. The sum of 


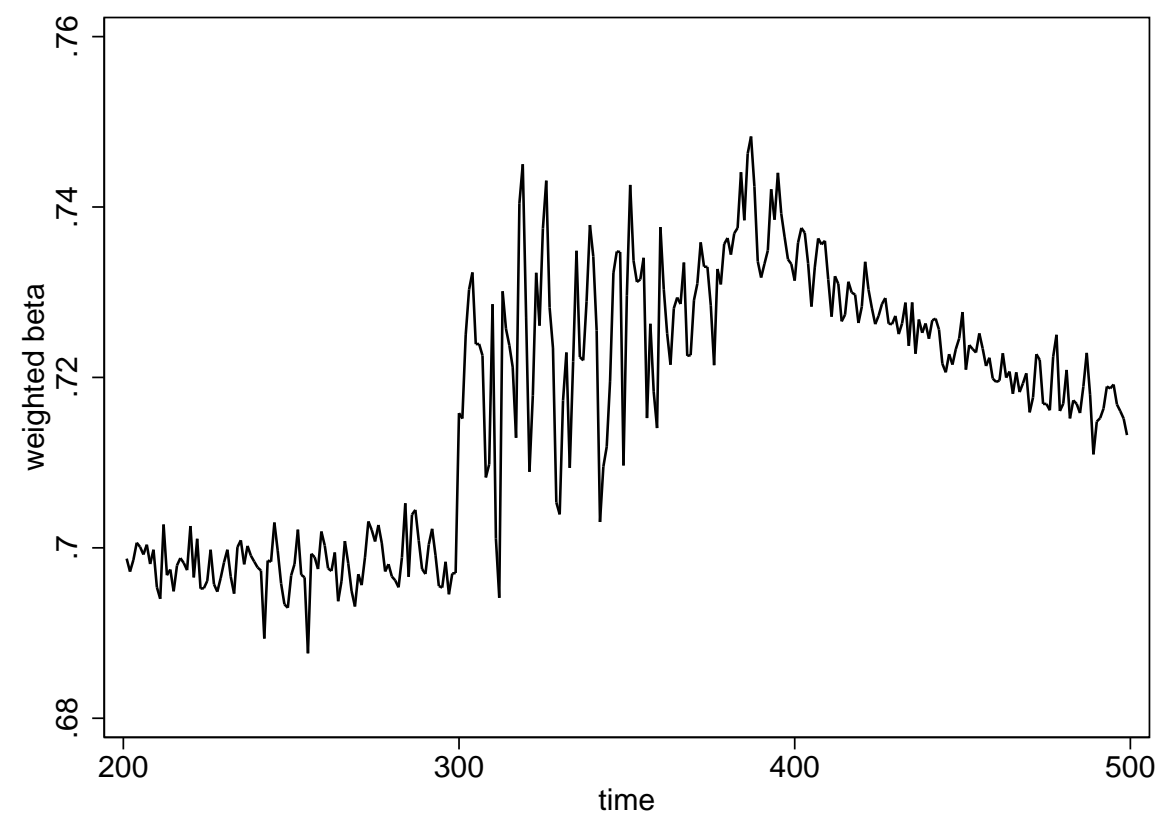

Figure 10: Average $\beta$ weighted by firm size 
the coefficients in the log-log regression, which corresponds to the returns to scale, averages 0.985 after the first shock, and 0.945 after the second shock. If the model is able to grasp something of the real world, it may be the case that the empirical evidence of a c.r.s. matching function could be valid only out-of-equilibrium.

\begin{tabular}{|c|c|c|c|c|c|c|}
\hline \multirow{3}{*}{$\begin{array}{l}\text { time } \\
y \\
x\end{array}$} & \multirow{2}{*}{\multicolumn{2}{|c|}{$\begin{array}{l}\text { 150-300 } \\
\text { equilibrium }\end{array}$}} & \multicolumn{2}{|c|}{$\begin{array}{c}350-500 \\
\text { back from shock } 1\end{array}$} & \multicolumn{2}{|c|}{$\begin{array}{c}550-650 \\
\text { back from shock } 2\end{array}$} \\
\hline & & & & & & \\
\hline & $\log u$ & $\log v$ & $\log u$ & $\log v$ & $\log u$ & $\log v$ \\
\hline run & \multicolumn{6}{|c|}{ sign of the coeff. } \\
\hline 0 & --- & --- & +++ & +++ & +++ & +++ \\
\hline 1 & --- & --- & +++ & +++ & +++ & +++ \\
\hline 2 & --- & --- & +++ & +++ & +++ & +++ \\
\hline 3 & --- & --- & +++ & +++ & +++ & +++ \\
\hline 4 & --- & --- & +++ & +++ & +++ & +++ \\
\hline 5 & --- & --- & +++ & +++ & +++ & +++ \\
\hline 6 & --- & --- & +++ & +++ & +++ & +++ \\
\hline 7 & --- & --- & +++ & +++ & +++ & +++ \\
\hline 8 & --- & --- & +++ & +++ & +++ & +++ \\
\hline 9 & --- & --- & +++ & +++ & +++ & +++ \\
\hline average & -1.161 & -.710 & .613 & .372 & .578 & .367 \\
\hline \multirow{2}{*}{$\begin{array}{l}\text { std.dev. } \\
\text { sum (r.s.) }\end{array}$} & .148 & .114 & .055 & .076 & .115 & .116 \\
\hline & \multicolumn{2}{|c|}{-1.871} & \multicolumn{2}{|c|}{0.985} & \multicolumn{2}{|c|}{0.945} \\
\hline $\begin{array}{l}* * * \\
* * \\
*\end{array}$ & \multirow{2}{*}{\multicolumn{6}{|c|}{$\begin{array}{l}\text { confidence interval }>.99 \\
\text { confidence interval }>.95 \\
\text { confidence interval }>.90\end{array}$}} \\
\hline$*=\{+,-\}$ & & & & & & \\
\hline
\end{tabular}

Table 5: The matching function

\section{Conclusions and directions for future work}

The model developed in this paper is a non-equilibrium, agent-based model of workers and firms, where workers have to decide whether to stay in their present state, look for another employee or start a new business themselves, and firms have to decide how many vacancies to open, and what wage they will offer to applicants. Workers and firms are heterogeneous, and learn their strategy in the labor market. On-the-job searching is allowed. The model is a non-equilibrium model because it does not make use of equilibrium conditions. However, it gives raise to stationary states, which can be regarded as the equilibrium of the model. In this sense equilibrium is not imposed; rather, it may emerge from the interaction of all individual behaviors.

The dynamics differ in the stationary and non-stationary state. The model exhibits a Beveridge curve with negative slope, which moves quickly inward and 
outward during the early phases of the transition process, and shows a typical spiral-like shape that eventually settles down to the traditional negative slope during the late phases of the adjustment processes, or for small adjustments. A negative sloped Okun curve is also recovered. There is no Wage curve in the stationary states, since wages are mainly driven by productivity, or when the labor market is too slack. However, a negative slope is observed in the final part of big adjustment process (or for small adjustment processes), when increasing competition between firms in the labor market forces salaries up. Moreover, during the transition processes the system exhibits a constant returns to scale matching function, which vanishes in the stationary state. Thus, the outcomes of the model are coherent with a description of the world as a disequilibrium process, continuously trying to adapt to a changing environment. One could thus question the appropriateness of equilibrium models based on these stylized facts, if they can be interpreted as just out-of-equilibrium properties of the real economies.

Two additional points need to be stressed. First, from a methodological point of view, the use of non-equilibrium computational models allows for a more comprehensive investigation of the labor market, by considering the endogenous character of many relevant variables. To this respect, the large number of stylized facts that the simple model of this paper is able to reproduce suggests that this approach could be "the most suitable starting point for the extensions that will eventually explain unemployment in real economies", as Pissarides put it.

Second, a need for a joint investigation of empirical regularities is identified. The model suggests that the shape of the Wage curve is not independent of the shape of the Beveridge and Okun curve, and both of them might be related to the matching function. The somehow fuzzy evidence on the existence and the slope of these curves may be due to the fact that the data considered by many empirical studies belong to different regimes, more or less distant from a stationary state. Great attention should then be paid to distinguishing between these different regimes, possibly with the help of the predictions of a model close in spirit to the one presented here. For instance, in this model the Beveridge curve acts as a good indicator of the transition process between different stationary states. Real data could then be grouped accordingly, in order to test some of the implications of the model. In correspondence with strong inward-outward shifts of the BC, according to the model, we should not be able to identify a Wage curve, while a negatively sloped WC should emerge when these shifts slow down. Moreover, the estimates of the matching function should also vary with the shape of the $\mathrm{BC}$, with a constant return to scale property being detectable only during its inward-outward shifts. As data on vacancies are often difficult to collect, one could look at the correlation between the coefficients of the matching function and the slope of the Wage curve. However, the empirical testing of the model, as well as a more accurate calibration of its structural parameters, are left for future research. 


\section{References}

[1] Philip Aghion and Paul Howitt, Growth and unemployment, Review of Economic Studies 61 (1994), no. 3, 477-494.

[2] J. W. Albrecht, P. A. Gautier, and S. B. Vroman, Matching with multiple applications, Economic Letters 78 (2003), 67-70.

[3] C. Attfield and B. Silverstone, Okun's coefficient: A comment, Review of Economics and Statistics 79 (1997), 326-329.

[4] Robert Axtell, Zipf distribution of u.s. firm size, Science 293 (2001), 18181820 .

[5] Brian Bell, Stephen Nickell, and Glenda Quintini, Wage equations, wage curves and all that, European Economic Review 9 (2002), 341-360.

[6] Olivier J. Blanchard and Peter Diamond, The aggregate matching function, Growth, Productivity, Unemployment, MIT Press, 1990.

[7] D. Blanchflower and A. Oswald, The wage curve, MIT Press, Cambridge, MA, 1994.

[8] K. Burdett, A theory of employee job search and quit rates, American Economic Review 68 (1978), 212-220.

[9] Ken Burdett, Shouyong Shi, and Randall Wright, Pricing and matching with frictions, Journal of Political Economy 109 (2001), no. 5, 1060-1085.

[10] R. J. Caballero and M. L. Hammour, The cleansing effect of recessions, American Economic Review 84 (1994), 1350-1368.

[11] David Card, The wage curve: A review, Journal of Economic Literature 33 (1995), 785-799.

[12] Peter Diamond, A model of price adjustment, Journal of Economic Theory 3 (1971), no. 2, 156-168.

[13] _ Mobility costs, frictional unemployment, and efficiency, Journal of Political Economy 89 (1981), no. 4, 798-812.

[14] _ Aggregate demand management in search equilibrium, Journal of Political Economy 90 (1982), no. 5, 881-894.

[15] - Wage determination and efficiency in search equilibrium, Review of Economic Studies 49 (1982), no. 2, 217-227.

[16] Giorgio Fagiolo, Giovanni Dosi, and Roberto Gabriele, Matching, bargaining, and wage setting in an evolutionary modelof labor market and outut dynamics, Advances in Complex Systems 7 (2004), no. 2, 157-186. 
[17] R. Fonseca, P. Lopez-Garcia, and C. A. Pissarides, Entrepreneurship, startup costs and unemployment, European Economic Review 45 (2001), $692-$ 705 .

[18] Edoardo Gaffeo, Mauro Gallegati, and Antonio Palestrini, On the size distribution of firms: Additional evidence from the $g^{7}$ countries, Physica A 324 (2003), 117-123.

[19] Domenico Delli Gatti, Corrado Di Guilmi, Edoardo Gaffeo, Gianfranco Giulioni, Mauro Gallegati, and Antonio Palestrini, Business cycle fluctuations and firms' size distribution dynamics, Advances in Complex Systems 7 (2004), 223-240.

[20] Boyan Jovanovic, Job matching and the theory of turnover, Journal of Political Economy 87 (1979), 973-990.

[21] Ricardo Lagos, An alternative approach to search frictions, Journal of Political Economy 108 (2000), no. 5, 851-873.

[22] Roberto Leombruni and Matteo Guido Richiardi, Why are economists sceptical about agent-based simulations?, Physica A (2005 (forthcoming)).

[23] Dale T. Mortensen, The matching process as a non-cooperative bargaining game, The Economics of Information and Uncertainty, University of Chicago Press, Chicago, 1982.

[24] _ Property rights and efficiency in mating, racing, and related games, American Economic Review 72 (1982), no. 5, 968-979.

[25] Dale T. Mortensen and C. A. Pissarides, Job creation and job destruction in the theory of unemployment, Review of Economic Studies 61 (1994), $397-415$.

[26] _ New developments in models of search in the labor market, Handbook of Labor Economics (O. C. Ashenfelter and D. Card, eds.), NorthHolland, Amsterdam, 1999.

[27] Derek Neal and Sherwin Rosen, The theory of earnings distributions, Handbook of Income Distribution (A. Atkinson and F. Bourgignon, eds.), NorthHolland, 2000.

[28] K. Okuyama, M. Takayasu, and H. Takayasu, Zipfs law in income distribution of companies, Physica A 269 (1999), 125-131.

[29] Barbara Petrongolo and C. A. Pissarides, Looking into the black box: A survey of the matching function, Journal of Economic Literature 39 (2001), 390-432.

[30] E.S. Phelps (ed.), Microeconomic foundations of employment and inflation theory, Norton, 1970. 
[31] Christopher A. Pissarides, Efficient job rejection, Economic Journal 94 (1984), 97-108.

[32] _ Search intensity, job advertising and efficiency, Journal of Labor Economics 2 (1984), no. 1, 128-143.

[33] _ Equilibrium unemployment theory, 2 ed., MIT Press, Cambridge, MA, 2000.

[34] M. Prachowny, Okun's law: Theoretical foundations and revised estimates, Review of Economics and Statistics 75 (1993), 331-336.

[35] Matteo G. Richiardi, A search model of unemployment and firm dynamics, Advances in Complex Systems 7 (2004), no. 2, 203-221.

[36] Richard Rogerson, Robert Shimer, and Randall Wright, NBER Working Papers (2004), no. 10655.

[37] Anthony E. Smith and Yves Zenou, A discrete-time stochastic model of job matching, Review of Economic Dynamics 6 (2003), no. 1, 54-79.

[38] Michele Sonnessa, The jas (java agent-based simulation) library, Industry and Labor Dynamics: The Agent-based Computational Economics Approach. Proceeding of the Wild@Ace 2003 conference" (Singapore) (R. Leombruni and M. Richiardi, eds.), World Scientific Press, 2004.

[39] G.J. Stigler, The economics of information, Journal of Political Economy 69 (1961), no. 2, 213-225.

[40] Leigh Tesfatsion, Agent-based computational economics: A constructive approach to economic theory, Handbook of Computational Economics, Volume 2: Agent-Based Computational Economics, North-Holland, 2005 (forthcoming). 


\begin{tabular}{|c|c|c|c|c|}
\hline & \multicolumn{4}{|c|}{ Ending state } \\
\hline $\begin{array}{l}\text { Starting } \\
\text { state }\end{array}$ & $U_{0}$ & $U_{+}$ & $E$ & $S$ \\
\hline$U_{0}$ & $P_{i, 0}$ & - & $1-P_{i, 0}$ & - \\
\hline$U_{+}$ & $\begin{array}{c}\left(1-H\left(\frac{w_{s t a r t}^{e}}{\bar{w}_{t}}\right)\right) P_{i, 0} \\
H\left(\frac{w_{s t a r t}^{e}}{\bar{w}_{t}}\right) P_{\omega, 0}\end{array}$ & $\begin{array}{c}\left(1-H\left(\frac{w_{s t a r t}^{e}}{\bar{w}_{t}}\right)\right) \\
(1-P i, 0) P_{\omega, 0}\end{array}$ & $\begin{array}{c}\left(1-H\left(\frac{w_{\text {start }}^{e}}{\bar{w}_{t}}\right)\right) \\
\left(1-P_{i, 0}\right)(1-P \omega, o)\end{array}$ & $H\left(\frac{w_{s t a r t}^{e}}{\bar{w}_{t}}\right)\left(1-P_{\omega, 0}\right)$ \\
\hline$E$ & $\begin{array}{l}\left(1-\Lambda\left(\frac{w_{\text {stay }}^{e}}{\bar{w}_{t}}\right)\right) \\
H\left(\frac{w_{s t a r t}^{e}}{\bar{w}_{t}}\right) P_{\omega, 0}\end{array}$ & 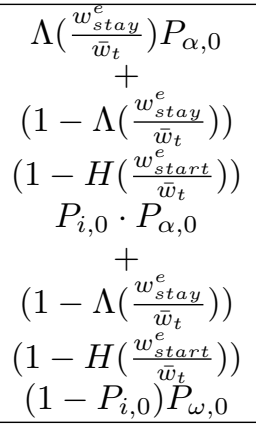 & 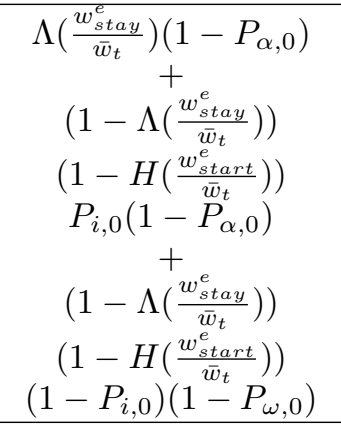 & $\begin{array}{c}\left(1-\Lambda\left(\frac{w_{\text {stay }}^{e}}{\bar{w}_{t}}\right)\right) \\
H\left(\frac{w_{\text {start }}^{e}}{\bar{w}_{t}}\right) \\
\left(1-P_{\omega, 0}\right)\end{array}$ \\
\hline$S$ & $\begin{array}{c}\Lambda\left(\frac{w_{s t a y}^{e}}{\bar{w}_{t}}\right) P_{\alpha, 0} \\
+ \\
\left(1-\Lambda\left(\frac{w_{s t a y}^{e}}{\bar{t}_{t}}\right)\right) \\
\left(1-H\left(\frac{w_{s t a r t}^{e}}{\bar{w}_{t}}\right)\right) \\
P_{i, 0} P_{\alpha, 0} \\
\left.\quad+\frac{w_{s t a y}^{e}}{P_{\bar{t}}^{e}}\right) \\
\left(1-\Lambda\left(\frac{w_{s}^{e}}{\bar{w}_{t}}\right)\right) \\
H\left(\frac{w_{s t a r t}^{e}}{\bar{w}_{t}}\right) P_{\omega, 0}\end{array}$ & $\begin{array}{c}\left(1-\Lambda\left(\frac{w_{\text {stay }}^{e}}{\bar{w}_{t}}\right)\right) \\
\left(1-H\left(\frac{w_{\text {start }}}{\bar{w}_{t}}\right)\right) \\
\left(1-P_{i, 0}\right) P_{\omega, 0}\end{array}$ & $\begin{array}{c}\left(1-\Lambda\left(\frac{w_{\text {stay }}^{e}}{\bar{w}_{t}}\right)\right) \\
\left(1-H\left(\frac{w_{\text {start }}^{e}}{\bar{w}_{t}}\right)\right) \\
\left(1-P_{i, 0}\right)\left(1-P_{\omega, 0}\right)\end{array}$ & $\begin{array}{c}\Lambda\left(\frac{w_{s t a y}^{e}}{\bar{w}_{t}}\right)\left(1-P_{\alpha, 0}\right) \\
++ \\
\left(1-\Lambda\left(\frac{w_{\text {stay }}^{e}}{\bar{t}_{t}}\right)\right) \\
\left(1-H\left(\frac{w_{s t a r t}^{e}}{\bar{e}_{t}}\right)\right) \\
P_{i, 0}\left(1-P_{\alpha, 0}\right) \\
+\bar{P}_{t}^{e} \\
\left(1-\Lambda\left(\frac{w_{\text {stay }}^{e}}{\bar{w}_{t}}\right)\right) \\
H\left(\frac{w_{s t a r t}^{e}}{\bar{w}_{t}}\right)\left(1-P_{\omega, 0}\right)\end{array}$ \\
\hline
\end{tabular}

Table 6: (Appendix) State Transition Matrix. $\Lambda\left(\frac{w_{s t a y}^{e}}{\bar{w}_{t}}\right)$, where $\Lambda$ is the cumulative distribution function of $\lambda_{i}$, is the probability of making a Stay decision. $H\left(\frac{w_{\text {start }}^{e}}{\bar{w}_{t}}\right)$, where $H$ is the cumulative distribution function of $\eta_{i}$, is the probability of making a Start decision, conditional on being active. $P_{i, 0}$ is said to be the probability that none of the applications sent out by individual $i$ is successful; $P_{\alpha, 0}$ the probability that the firm where the individual $i$ was working before the move, if any, is closed down, and $P_{\omega, 0}$ the probability that the firm where the individual $i$ is working after the move, if any, is closed down. 